ARTICLE

\title{
Modular and stereoselective synthesis of tetrasubstituted vinyl sulfides leading to a library of AlEgens
}

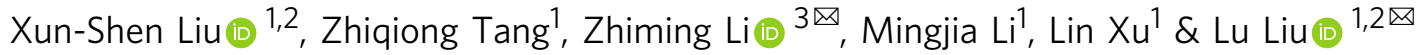

Tetraarylethylenes exhibit intriguing photophysical properties and sulfur atom frequently play a vital role in organic photoelectric materials and biologically active compounds. Tetrasubstituted vinyl sulfides, which include both sulfur atom and tetrasubstituted alkenes motifs, might be a suitable skeleton for the discovery of the new material molecules and drug with unique functions and properties. However, how to modular synthesis these kinds of compounds is still challenging. Herein, a chemo- and stereo-selective Rh(II)-catalyzed [1,4]-acyl rearrangements of $\alpha$-diazo carbonyl compounds and thioesters has been developed, providing a modular strategy to a library of 63 tetrasubstituted vinyl sulfides. In this transformation, the yield is up to $95 \%$ and the turnover number is up to 3650 . The mechanism of this reaction is investigated by combining experiments and density functional theory calculation. Moreover, the "aggregation-induced emission" effect of tetrasubstituted vinyl sulfides were also investigated, which might useful in functional material, biological imaging and chemicalnsing via structural modification.

\footnotetext{
${ }^{1}$ School of Chemistry and Molecular Engineering, East China Normal University, 500 Dongchuan Road, Shanghai 200241, China. ${ }^{2}$ Shanghai Engineering Research Center of Molecular Therapeutics and New Drug Development, East China Normal University, 3663 N Zhongshan Road, Shanghai 200062, China.

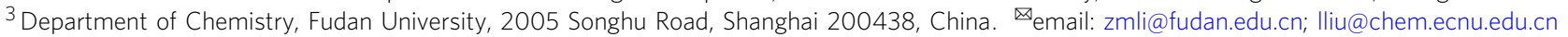


O rganosulfur chemistry has attracted more and more attention and brought increasing significance because carbon-sulfur bonds widely exist in nature, including biologically active molecules ${ }^{1-4}$, pharmaceuticals ${ }^{5}$, agrochemicals $^{6}$, materials ${ }^{7}$, flavors, and fragrances ${ }^{8}$, and even food ingredients 9 . Sulfur-containing motifs frequently play a vital role in organic photoelectric materials and biologically active compounds because $\mathrm{S}$ atom possesses strong polarizability and hyperpolarizability. Meanwhile, since the concept of "aggregation-induced emission" (AIE) was disclosed by Tang and coworkers ${ }^{10-21}$ in 2001, the development of new AIE luminogens (AIEgens) has attracted significant attention during the past few years because of the enormous application potential in organic light-emitting diodes (OLEDs) ${ }^{22,23}$, biological imaging ${ }^{24,25}$, chemical sensors 26,27 , cancer ablation ${ }^{28,29}$, and theranostics ${ }^{30,31}$. Thus, the introducing of $\mathrm{S}$ atom into tetrasubstituted alkenes, one type of the classical AIE gens, might be an efficient way for the development of new material molecules with unique functions and properties (Fig. 1a).

Diazo compounds, especially a-diazocarbonyl compounds which are easily prepared and handled, are highly important reagents in synthetic chemistry, because they have high and versatile reactivity which have been used in a series of carbene transfer reactions including $\mathrm{X}-\mathrm{H}(\mathrm{X}=\mathrm{O}, \mathrm{N}, \mathrm{S}, \mathrm{C}$, etc.) insertion, cyclopropanation, and ylide formation under the catalysis of transition metals ${ }^{32-37}$. They are also used frequently for the synthesis of sulfides via the construction of $\mathrm{C}-\mathrm{S}$ bond ${ }^{38-42}$. In this regard, rearrangements via sulfonium ylides offer a straightforward and versatile way of accessing sulfide with carbonyl groups, which include [1,2]-rearrangement (Stevens rearrangement ${ }^{43-46}$ ) and [2,3]-rearrangement (Doyle-Kirmse rearrangement $^{47-52}$, and Sommelet-Hauser rearrangement ${ }^{53-55}$ ). However, these reactions could only afford the products with $\mathrm{C}\left(\mathrm{sp}^{3}\right)-\mathrm{S}$ bond (Fig. 1b). Although Wang et al. reported an aromatic indolyl $\mathrm{C}\left(\mathrm{sp}^{2}\right)-\mathrm{S}$ bond formation from the reaction of 3-diazoindol-2-imines with thioesters ${ }^{56}$, the formation of vinyl $\mathrm{C}\left(\mathrm{sp}^{2}\right)-\mathrm{S}$ bond via the sulfonium ylides rearrangement of the reaction of sulfur-containing compounds with diazo compounds is still unknown.

In this work, based on our continuous interest in transitionmetal catalyzed carbene transfer reaction of $\alpha$-diazo carbonyl compounds ${ }^{57-59}$, we describe herein that structurally diverse tetrasubstituted vinyl sulfides (TVSs) are modularly assembled for the first time by a rhodium-catalyzed ylide formation/[1,4]acyl transfer reaction of S-acyl thiol and diazo compounds (Fig. 1c).

\section{a Tetrasubstituted alkenes and sulfur atom in material science}<smiles>c1ccc(C(=C(c2ccccc2)c2ccccc2)c2ccccc2)cc1</smiles>

TPE<smiles>c1ccc2c(c1)sc1c3ccccc3sc21</smiles>

BTBT

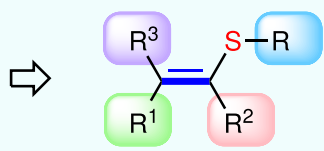

TVS

b Rearrangement of sulfonium ylides (from $\mathrm{S}$ to $\mathrm{C}$ )

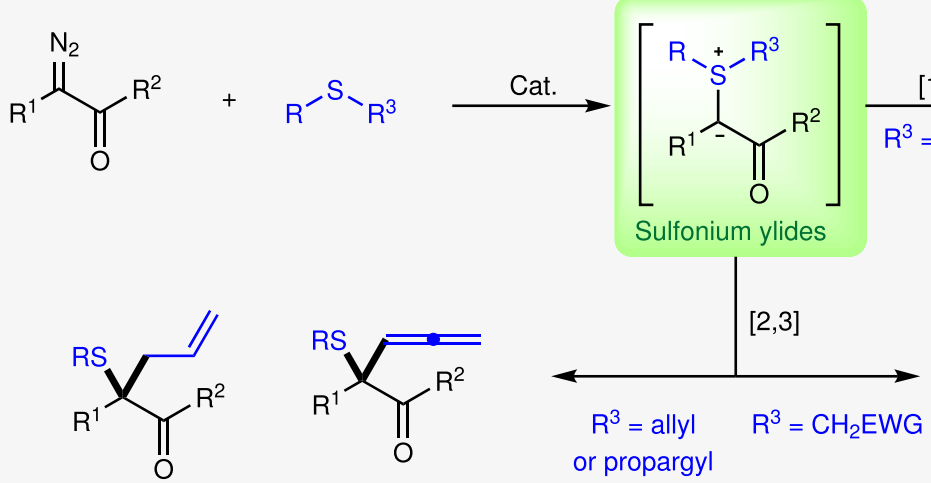

Doyle-Kirmse Rearrangement<smiles>[R]C(=O)C([R7])([R5])[B]</smiles>

Stevens Rearrangement<smiles>[R]C(=O)Cc1ccccc1C([R5])C(C)(C)C</smiles>

Sommelet Rearrangement

C This work: $[1,4]$-acyl transfer (from $\mathrm{S}$ to $\mathrm{O}$ )

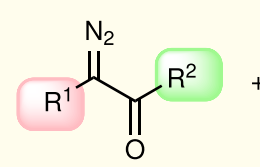

2

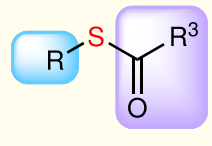

1

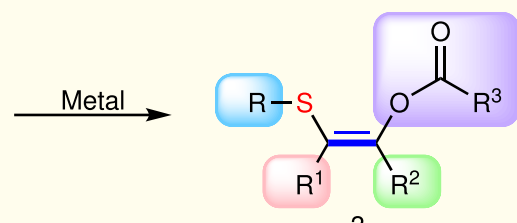

3

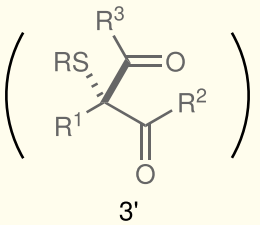

$[1,2]$-acyl transfer not detected

Fig. 1 The reactions of sulfur nucleophiles and diazo carbonyl compounds. a The design of new AlEgens. $\mathbf{b}$ Three classical rearrangement reactions via sulfur ylide. c 1,4-acyl transfer strategy of diazoketone and thioester. TPE: 1,1,2,2-tetraphenylethylene, BTBT: benzthieno[3,2-b]benzothiophene; TVS: tetrasubstituted vinyl sulfides. 


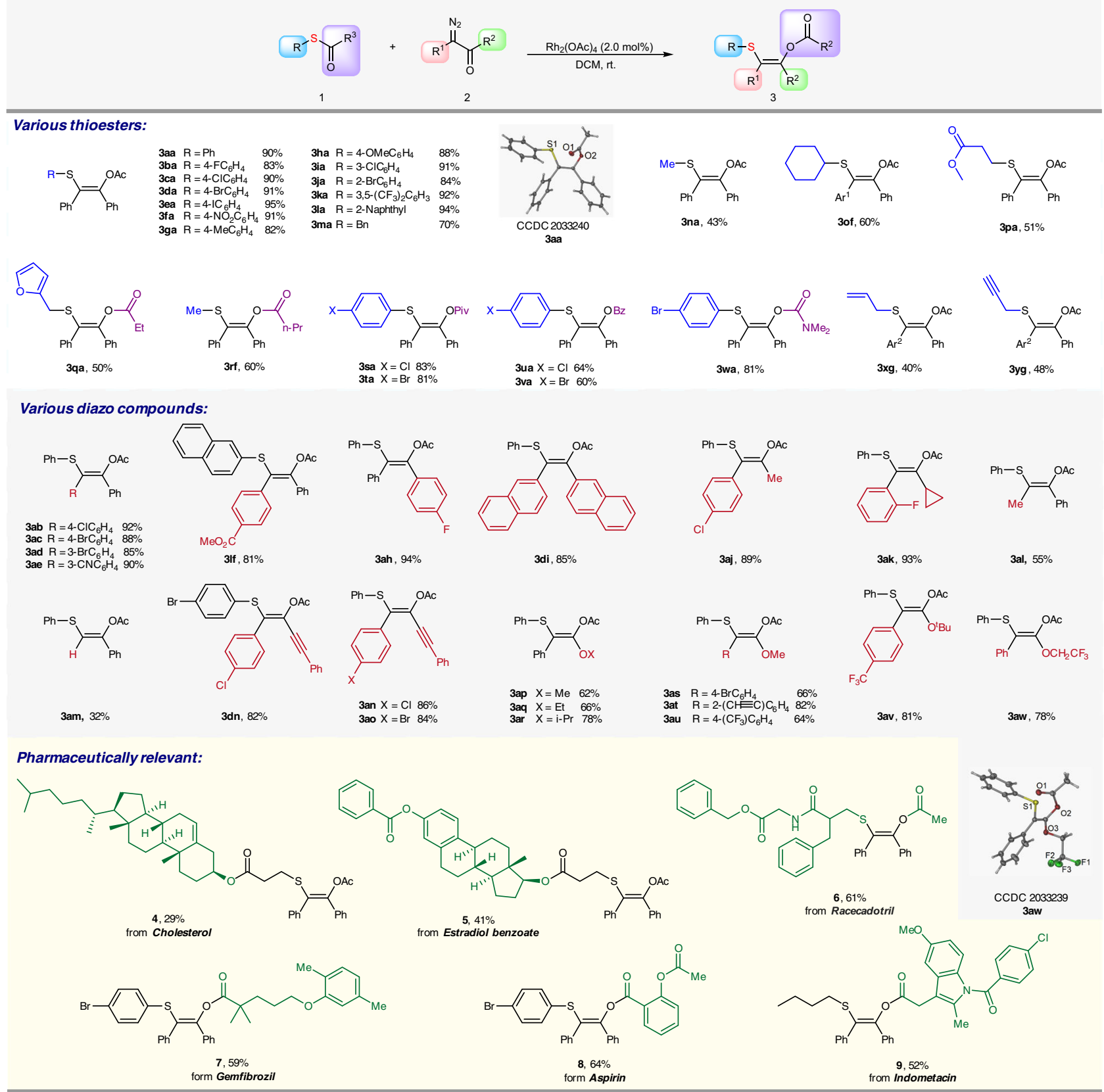

Fig. 2 Substrate scope. Reaction conditions: to the solution of $1(0.5 \mathrm{mmol})$ and $\mathrm{Rh}_{2}(\mathrm{OAc})_{4}(0.01 \mathrm{mmol}, 2 \mathrm{~mol} \%)$ in $1.0 \mathrm{~mL} \mathrm{DCM}$, the mixture of 2 $(0.75 \mathrm{mmol})$ and $\mathrm{DCM}(1.0 \mathrm{~mL})$ was added dropwise in $5 \mathrm{~min}$ at room temperature. Isolated yields for all $\mathrm{TVSs} \mathrm{Ar}^{1}=p-\mathrm{CO}_{2} \mathrm{MePh}, \mathrm{Ar}^{2}=m-\mathrm{CO}_{2} \mathrm{EtPh}$.

\section{Results}

Substrate scope of $[1,4]$-acyl transfer reaction. Initially, the reaction of acetyl phenthiol $\mathbf{1 a}$ and phenyl diazo ketone $\mathbf{2 a}$ was chosen as the model reaction. After screening the condition, $\mathrm{Rh}_{2}(\mathrm{OAc})_{4}$ was proven the best catalyst for this transformation (see Supplementary Table 1). We then tested the substrate scope of this $[1,4]$-acyl transfer reaction. As shown, a diverse range of $S$ aryl ethanethioate, with different substitutes on para-, meta-, and ortho-positions of phenyl ring, were suitable substrates for $[1,4]$ acetyl transfer reaction, affording the corresponding tetrasubstituted Z-olefins 3aa-3ka in good to excellent yields with excellent chemo- and stereo-selectivity (Fig. 2). To our delight, the alkyl groups, including benzyl, cyclohexyl, ester-containing alkyl, on the sulfur atom were tolerated (Fig. 2, 3ma-3pa). It was noteworthy that the well-known Stevens rearrangement had not been observed in this transformation. When aryl thiol with various acyl groups with steric hindrance and carbamoyl group on sulfur atom were tested in this transformation, the same $[1,4]$ acyl and carbamoyl transfer took place, affording the corresponding Z-olefins in good efficiency (Fig. 2, 3qa-3wa). Interestingly, attempts using the ethanethioate with allyl and propargyl on $S$ atom exclusively delivered the acyl transfer products without any [2,3]-rearrangement products being detected (Fig. 2, 3xg3yg). Next, we began to study the substrate scope of various diazo carbonyl compounds 2. Diazo ketones $\mathbf{2 b - 2 o}$ containing various substituents, including aryl, alkyl, alkynyl, and hydrogen were compatible, delivering the expected products $\mathbf{3 a b}-\mathbf{3 a o}$ in good yields. Notably, diazoesters were compatible and delivered the alkene products in good yields with single Z-selectivity (Fig. 2, 3ap-3aw). Furthermore, this protocol was also applicable to 

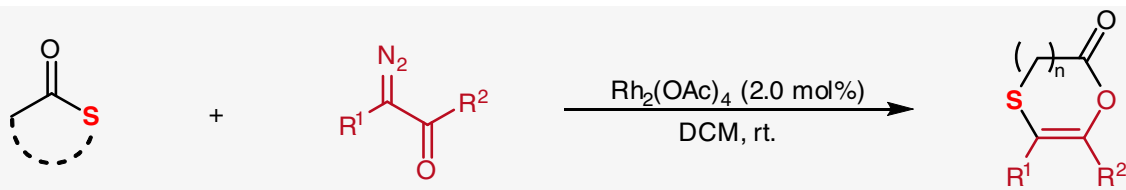

10

11, yield<smiles>O=C1OC(c2ccccc2)=C(c2ccccc2)SCC12CCCCC2</smiles>

$11 a, 73 \%$

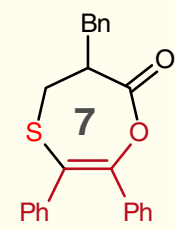

$11 b, 52 \%^{a}$

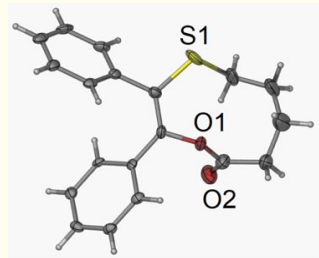

CCDC 2033242 11d

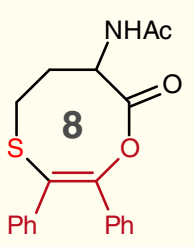

$11 c, 80 \%$

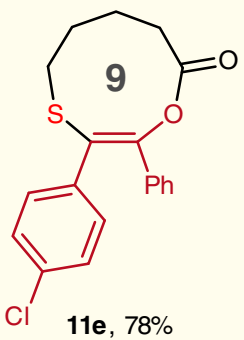

$11 e, 78 \%$

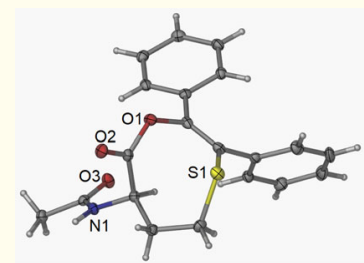

CCDC 2033243 $11 \mathrm{c}$

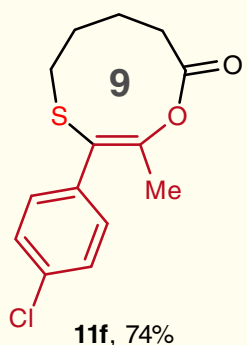

11f, $74 \%$<smiles>O=C1CCCCSc2c(ccc3ccccc23)O1</smiles>

$11 g, 52 \%$<smiles>O=C1Cc2ccccc2CS/C(c2ccccc2)=C(\c2ccccc2)O1</smiles>

$11 \mathrm{~h}, 62 \%$

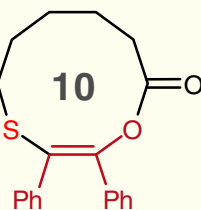

$11 i, 53 \%^{\mathrm{a}}$

Fig. 3 Ring expansion reaction of thiolactones $\mathbf{1 0}$ with diazoketones 2. Reaction conditions: to the solution of $\mathbf{1 0}(0.5 \mathrm{mmol})$ and $\mathrm{Rh}_{2}(\mathrm{OAc})_{4}(0.01 \mathrm{mmol}$, $2 \mathrm{~mol} \%)$ in $1.0 \mathrm{~mL} \mathrm{DCM}$, the mixture of $\mathbf{2}(0.75 \mathrm{mmol})$ and DCM $(1.0 \mathrm{~mL})$ was added dropwise in $5 \mathrm{~min}$ at room temperature. Isolated yields for all TVSs. aThe reaction scale is $0.4 \mathrm{mmol}$.

pharmaceutically relevant molecules due to the mild reaction conditions and convenient operation. To our delight, Cholesterol, Estradiol, Racecadotril, Gemfibrozil, Aspirin, and Indometacin derivatives gave the $[1,4]$-acyl migration products 4-9 in moderate to good yields. The structures of 3aa and 3aw were further confirmed by single-crystal X-ray crystallography analysis.

Then, we envisaged that the analogous $[1,4]$-acyl migration reaction should be applicable to the cyclic thioester substrate, which would undergo the ring expanding reaction by three atoms and afford medium-sized lactones containing an alkenyl sulfide moiety. When the spiro four-membered ring thiolactone 10a reacted with diazoketones $\mathbf{2 a}$ under the standard condition, the seven-membered lactone 11a was generated in $73 \%$ isolated yield via the sequential ylide formation/[1,4]-acyl migration as we expected. Thus, various thiolactones $\mathbf{1 0}$ equipped with the rings from four-member to seven-member were tested (Fig. 3). All the reactions of 10 with diazoketone $\mathbf{2}$ were carried out smoothly, affording the corresponding lactone 11b-11i with sevenmembered to ten-membered rings in moderate to good yields. It was noteworthy that the reaction of thiolactone with amide group gave the ring expansion product 11c without the $\mathrm{N}-\mathrm{H}$ insertion product. This result indicates this tandem ylide formation/acyl migration reaction exhibited excellent chemoselectivity, which occurred preferentially over the $\mathrm{N}-\mathrm{H}$ insertion reaction. The structures of $11 \mathrm{c}$ and $\mathbf{1 1 e}$ were further confirmed by single-crystal X-ray crystallography analysis (Fig. 3).

Gram-scale reaction and the transformations of products. As shown in Fig. 4, this [1,4]-acyl migration reaction of thioester and diazoketones was easy to scale-up. The $5 \mathrm{mmol}$ scale reaction of 2a and 1 a was carried out under $0.1 \mathrm{~mol} \% \mathrm{Rh}_{2}(\mathrm{OAc})_{4}$, furnishing $1.44 \mathrm{~g}$ of the desired product $3 \mathrm{aa}$ in $83 \%$ yield. Gratifyingly, the catalyst loading could be further decreased to $0.02 \mathrm{~mol} \%$ without effect on the yield, and the TON was up to 3650 . The $22.5 \mathrm{mmol}$ scale reaction of $\mathbf{2 a}$ and $\mathbf{1 d}$ could give $6.988 \mathrm{~g}$ of the corresponding product $\mathbf{3 d a}$ in $73 \%$ yield. It should be noted that $\mathbf{3 d a}$ could be obtained after simple recrystallization instead of column chromatography (see Supplementary Fig. 1 for details), demonstrating the promising synthetic practicality of this reaction. To examine the synthetic value of this protocol further, several transformations of $\mathbf{3 a a}$ and $\mathbf{3 d a}$ were also performed (Fig. 4). 


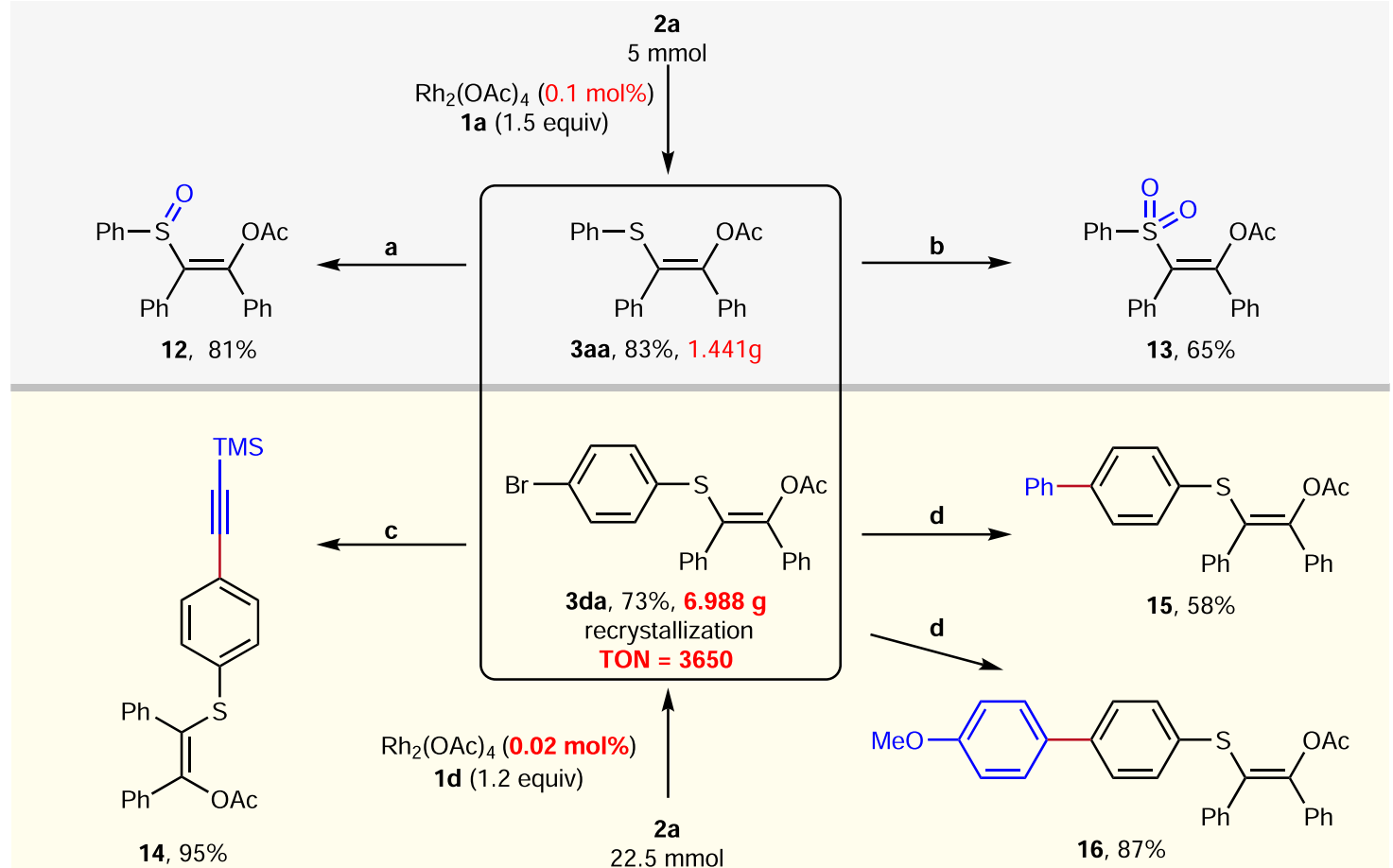

Fig. 4 Gram-scale reaction and the transformations of products. a $m$ - $\mathrm{CPBA}\left(1.2\right.$ equiv), $\mathrm{NaHCO}_{3}\left(1.0\right.$ equiv), $\mathrm{DCM}, \mathrm{O}^{\circ} \mathrm{C} . \mathbf{b} \mathrm{m}-\mathrm{CPBA}\left(5.0\right.$ equiv), $\mathrm{NaHCO}{ }_{3}$ (1.0 equiv), $\mathrm{DCM}, \mathrm{O}^{\circ} \mathrm{C} . \mathbf{c} \mathrm{Pd}\left(\mathrm{PPh}_{3}\right)_{2} \mathrm{Cl}_{2}(5 \mathrm{~mol} \%), \mathrm{Cul}(5 \mathrm{~mol} \%)$, trimethylsilylacetylene (2 equiv), $\mathrm{Et}_{3} \mathrm{~N}, 80^{\circ} \mathrm{C}, 3 \mathrm{~h} . \mathbf{d} \mathrm{Pd}\left(\mathrm{PPh}_{3}\right){ }_{4}\left(10 \mathrm{~mol}^{2}\right), \mathrm{Na} \mathrm{CO}_{3}$ (2.0 equiv), $\mathrm{ArB}(\mathrm{OH})_{2}\left(1.5\right.$ equiv), toluene: $\mathrm{H}_{2} \mathrm{O}=1: 1,100^{\circ} \mathrm{C}, 3 \mathrm{~h}$.<smiles>CCC(=O)Sc1ccc(OC)cc1</smiles><smiles>CC(=O)Sc1ccc(Cl)cc1</smiles>

2a (3.0 equiv) $\stackrel{\mathrm{Rh}_{2}(\mathrm{OAc})_{4}(2.5 \mathrm{~mol} \%)}{\longrightarrow}$ DCM, rt.<smiles>CCOC(=O)/C(=C(/Sc1ccc(OC)cc1)c1ccccc1)c1ccccc1</smiles>

3za, $87 \%$<smiles>CC(=O)O/C(=C(\c1ccccc1)c1ccc(Cl)cc1)c1ccccc1</smiles>

3ca, $84 \%$

\section{Not observed}<smiles>COc1ccc(S/C(=C(\OC(C)=O)c2ccccc2)c2ccccc2)cc1</smiles>

3ha<smiles>CCC(=O)O/C(=C(\Sc1ccc(Cl)cc1)c1ccccc1)c1ccccc1</smiles>

3ca'

Fig. 5 Crossover experiment. Reaction conditions: $\mathbf{1 z}(0.5 \mathrm{mmol})$, 1c $(0.5 \mathrm{mmol})$, and $\mathrm{Rh}_{2}(\mathrm{OAc})_{4}(0.025 \mathrm{mmol}, 2.5 \mathrm{~mol} \%)$ in $2.0 \mathrm{~mL} \mathrm{DCM}, \mathbf{2 a}(1.5 \mathrm{mmol})$, and DCM $(2.0 \mathrm{~mL}$ ) was added dropwise in $10 \mathrm{~min}$ at room temperature. Isolated yields for $\mathbf{3 z a}$ and $\mathbf{3} \mathbf{c a}$.

When the 3aa was treated with $m$-CPBA, vinyl sulfoxide (12) and vinyl sulfone (13) could be obtained in $81 \%$ and $65 \%$ yields, respectively (Fig. 4a, b). Meanwhile, the cross-coupling of 3da with terminal alkyne and aryl boronic acid afforded the corresponding products 14-16 in moderate to excellent yields (Fig. 4c, d).

Crossover experiment. In order to understand the reaction mechanism, a crossover experiment was conducted (Fig. 5). As a result, the expected non-crossover products $\mathbf{3 z a}$ and $3 \mathbf{c a}$ were obtained in excellent yields and no crossover products (3ha or $3 \mathbf{c a}^{\prime}$ ) was observed in the crude ${ }^{1} \mathrm{H}$ NMR. This results proved this $[1,4]$-migration was a concerted rearrangement pathway.
DFT calculations. To further understand the mechanism of this reaction, density functional theory (DFT) calculations were then carried out with the Gaussian 09 software package ${ }^{60-63}$. The calculation details were provided in the Supplementary Information. The reaction of $\mathbf{2 a}$ and $\mathbf{1 a}$ was selected as the model reaction. As illustrated in Fig. 6, the reaction path included the formation of rhodium carbene intermediate Int-1, then the generation of free sulfur ylide Int-3 via a metal-bound ylide intermediate Int-2, and finally [1,4]-shift of acetyl group to form product 3aa, in which the formation of rhodium carbene $\mathbf{A}$ was the determining step. The barrier was $23.5 \mathrm{kcal} / \mathrm{mol}$, which meant this reaction can proceed smoothly at room temperature. This was in good line with the experiment. The [1,4]-shift of acetyl process is almost barrierless, with a barrier of only $1.1 \mathrm{kcal} / \mathrm{mol}$. 


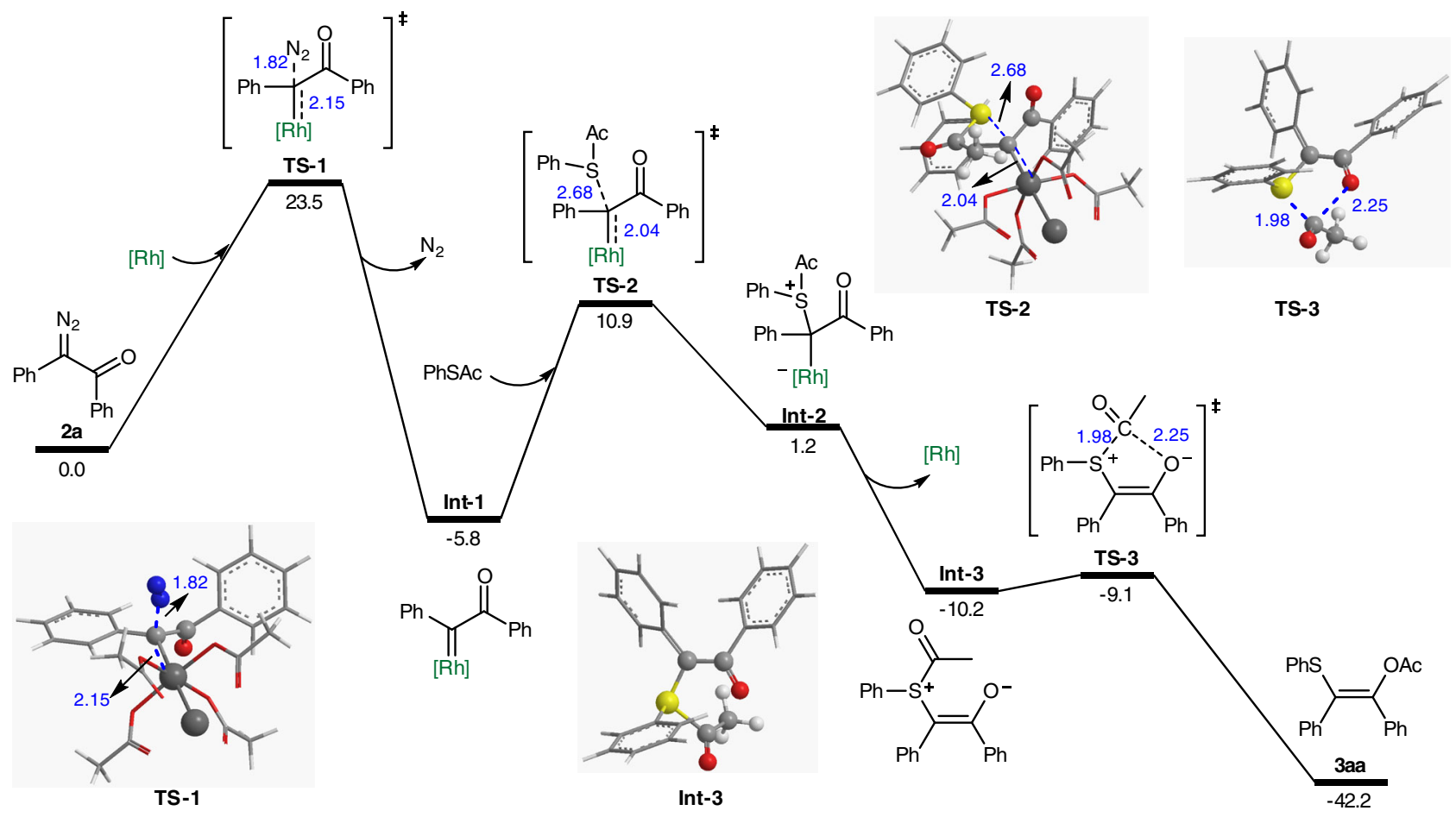

Fig. 6 DFT calculations. Computational exploration for the reaction of $\mathbf{2 a}$ and $\mathbf{1 a}$. $[R h]=\mathrm{Rh}_{2}(\mathrm{OAc})_{4}$.

The rhodium carbene intermediate to coordinate with the carbonyl oxygen of the thioester Int-2' was located, while the relative free energy is $3.3 \mathrm{kcal} / \mathrm{mol}$ higher than that with sulfur. Furthermore, we also located a more stable rhodium-stabilized acylsulfur ylide Int-3' by $-6.5 \mathrm{kcal} / \mathrm{mol}$, compared to Int-2 (see Supplementary Fig. 2 for more details). While the corresponding 1,4 -acyl migration process is less favored than the free ylide, the free energy difference between two TSs (TS-3 and TS-3') is up to $6 \mathrm{kcal} / \mathrm{mol}$. So the free ylide should be the intermediate in this reaction.

This barrier was lower than that of [2,3]-rearrangement of allyl and propargyl, which could explain the excellent chemoselectivity of this reaction (see Supplementary Figs. 3 and 4 for more details). Furthermore, this calculation demonstrated that this $[1,4]$-acyl migration presumably proceeds via a free ylide intermediate, which was consistent with the known $[1,4]$-acyl migration from $\mathrm{O}$ to $\mathrm{C}^{64}$.

Photophysical properties of TVSs. Having established this protocol to conveniently construct the library of tetrasubstituted vinyl sulfides (TVSs), we then tested the photophysical properties of these molecules. Classic AIE was observed by dissolving $\mathbf{3} \mathbf{c a}$ in the mixture solution of 1,4-dixoane and water with different fractions of water. Compound $3 \mathrm{ca}$ showed almost no fluorescence in 1,4-dixoane. With the gradual addition of water into the solution of $3 \mathrm{ca}$ in 1,4-dixoane, the emission intensity increased slightly when water fraction was less than $70 \%$. However, when water fraction exceeded $70 \%$, the emission intensity of $\mathbf{3 c a}$ increased significantly since the restriction of intramolecular rotation (Fig. 7a, b, d). All the TVSs with cis-1,2-diaryl substituents exhibit this phenomenon, and the fluorescence emission spectra of representative vinyl sulfides were also measured and the emission maxima of all the AIE-gens altered from 418 to $442 \mathrm{~nm}$ (Fig. 7c, and see Supplementary Information for details). The results indicated the substituents on diazo compounds 2 were vital for the AIE-activity of the producing vinyl sulfides. The TVSs with two aryls or one aryl and one alkynyl exhibited AIE- activity, while the olefins containing $\mathrm{H}$, alkyl, and alkoxyl did not have AIE effect. Moreover, some AIEgens, such as 3aa, 3ca, 3da, 3sa, 3dn, and 15, exhibted interesting luminescence in solid state (Fig. 7c, and see Supplementary Table 7 for more details). Thus, these compounds might be useful for OLEDs and living animal imaging via structural modification.

\section{Discussion}

In summary, we have developed a rhodium-catalyzed rearrangement reaction of thioesters and diazoketones via sulfur ylide, which provides a modular strategy to construct a library of tetrasubstituted vinyl sulfides (TVSs) in good to excellent yields. This protocol features broad substrate scope (63 examples), mild condition, low catalytic loading, convenient operation, and easy scale-up. The TON of this reaction is up to 3650 and the product can be isolated without column, indicating that this reaction might be promising tools in industry. The mechanistic studies combining experiments and DFT calculation exhibit this $[1,4]$ acyl shift from $\mathrm{S}$ to $\mathrm{O}$ is intramolecular pathway and has lower energy bar than known [2,3]-rearrangement via a free ylide intermediate. Furthermore, the spectroscopic properties of these molecules were studied in solution as well as solid state, and TVS is proved to be a new type of AIEgens. Some of them might be useful for OLEDs and living animal imaging via structural modification. This work would inspire the development of new sulfur-containing AIEgens and broaden the application of catalytic reactions in synthesis of materials.

\section{Methods}

General procedure for TVSs. Thioester 1 or $10(0.5 \mathrm{mmol}, 1.0$ equiv), and $\mathrm{Rh}_{2}(\mathrm{OAc})_{4}(0.01 \mathrm{mmol}, 2.0 \mathrm{~mol} \%)$ were introduced into a dried glass tube under $\mathrm{N}_{2}$ protection, and add $1 \mathrm{~mL}$ dry DCM as solvent, then the diazoketone 2 $(0.75 \mathrm{mmol}, 1.5$ equiv) was dissolved in $1 \mathrm{ml}$ of DCM and add dropwise in $5 \mathrm{~min}$ at room temperature. After the addition, continue to react for 1 min consumed diazo completely determined by TLC analysis. The mixture was purified by column chromatography on silica gel using PE/EtOAc as the eluent and concentrated to obtain the product 3 or 11. All new compounds were fully characterized (see the Supplementary Information). 
a

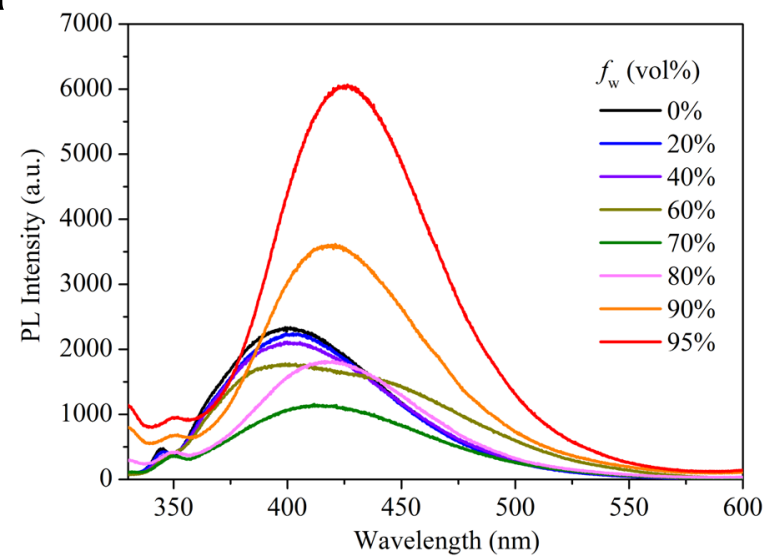

C

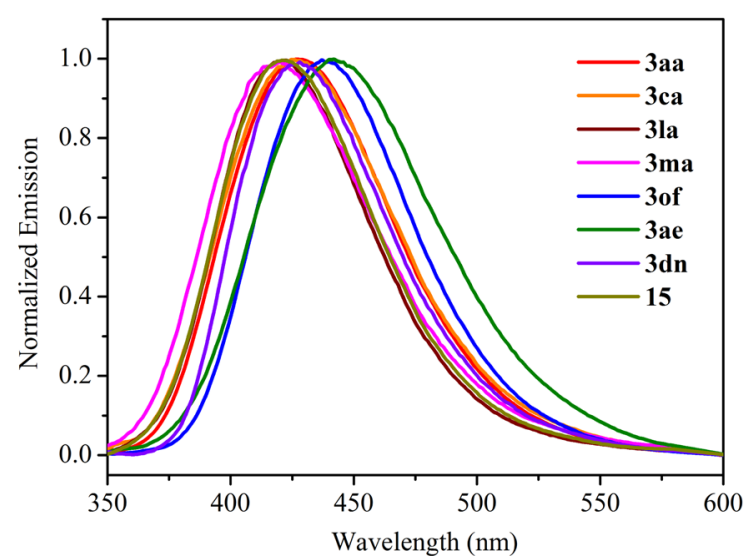

b

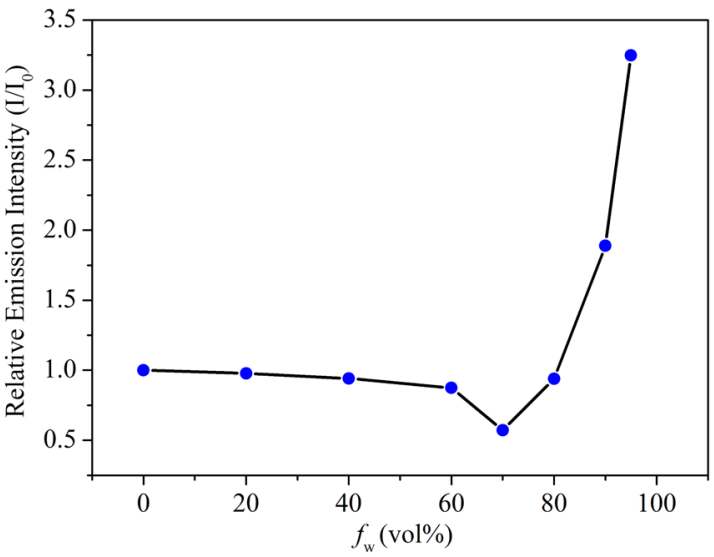

d

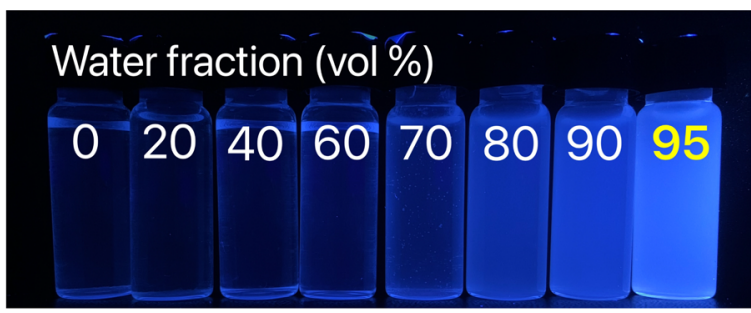

e



3aa

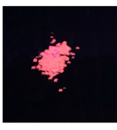

$3 \mathrm{ca}$

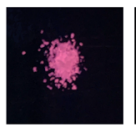

3da

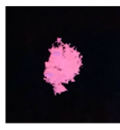

3sa

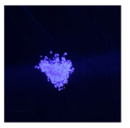

$3 d n$

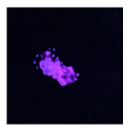

15

Fig. 7 Photophysical property test. a Emission spectra of 3ca obtained at different water fractions of the 1,4-dixoane/water solvent mixtures. b Relative emission intensity of compound $\mathbf{3 c a}$ a in 1,4-dioxane $/ \mathrm{H}_{2} \mathrm{O}$ mixture with increasing water fractions $\left(f_{\mathrm{w}}\right)$ to $95 \%\left(c=150 \mu \mathrm{M}, \lambda_{\mathrm{ex}}=312 \mathrm{~nm}, \lambda_{\mathrm{em}}=426 \mathrm{~nm}\right)$. c Normalized fluorescence emission spectra in 1,4-dixoane/water mixtures ( $c=150 \mu \mathrm{M}, 95 \%$ water) of selected vinyl sulfide. d 3ca $(c=150 \mu \mathrm{M})$ in $1,4-$ dixoane/water mixtures with different volume fractions of water and e photographs of solid compounds; all photographs taken upon excitation at $365 \mathrm{~nm}$ using a UV lamp at $298 \mathrm{k}$.

\section{Data availability}

All other data in support of the findings of this study are available within the Article and its Supplementary Information or from the corresponding author upon request. X-ray crystallographic data for compound 3aa (CCDC 2033240), 3aw (CCDC 2033239), 11c (CCDC 2033243), and 11e (CCDC 2033242) are freely available from the Cambridge Crystallographic Data Center. Copies of the data can be obtained free of charge from the Cambridge Crystallographic Data Center via https://www.ccdc.cam.ac.uk/data_request/cif.

Received: 20 April 2021; Accepted: 3 November 2021; Published online: 15 December 2021

\section{References}

1. Stiefel, E. I. in Transition Metal Sulfur Chemistry: Biological and Industrial Significance 2-38 (American Chemical Society, 1996).

2. Fontecave, M., Ollagnier-de-Choudens, S. \& Mulliez, E. Biological radical sulfur insertion reactions. Chem. Rev. 103, 2149-2166 (2003).

3. Wang, B.-W. et al. 1,1-Diphenylvinylsulfide as a functional AIEgen derived from the aggregation-caused-quenching molecule 1,1-diphenylethene through simple thioetherification. Angew. Chem. Int. Ed. 59, 2338-2343 (2020).

4. Biesen, L., Nirmalananthan-Budau, N., Hoffmann, K., Resch-Genger, U. \& Müller, T. J. J. Solid-state emissive aroyl-S, N-ketene acetals with tunable aggregation-induced emission characteristics. Angew. Chem. Int. Ed. 59, 10037-10041 (2020)

5. Ilardi, E. A., Vitaku, E. \& Njardarson, J. T. Data-mining for sulfur and fluorine: an evaluation of pharmaceuticals to reveal opportunities for drug design and discovery. J. Med. Chem. 57, 2832-2842 (2014).

6. Casida, J. E. \& Durkin, K. A. Pesticide chemical research in toxicology: lessons from nature. Chem. Res. Toxicol. 30, 94-104 (2017).
7. Cinar, M. E. \& Ozturk, T. Thienothiophenes, dithienothiophenes, and thienoacenes: syntheses, oligomers, polymers, and properties. Chem. Rev. 115, 3036-3140 (2015).

8. Wang, M., Wang, C. \& Jiang, X. Recent progress in the sulfur-containing perfume \& flavors construction. Chin. J. Org. Chem. 39, 2139-2147 (2019).

9. Lin, D. Y., Zhang, S. Z., Block, E. \& Katz, L. C. Encoding social signals in the mouse main olfactory bulb. Nature 434, 470-477 (2005).

10. Luo, J. et al. Aggregation-induced emission of 1-methyl-1,2,3,4,5pentaphenylsilole. Chem. Commun. 18, 1740-1741 (2001).

11. Huang, G. et al. Multiple anti-counterfeiting guarantees from a simple tetraphenylethylene derivative-high-contrasted and multi-state mechanochromism and photochromism. Angew. Chem. Int. Ed. 58, 17814-17819 (2019).

12. Liu, B. \& Tang, B. Z. Aggregation-induced emission: more is different. Angew Chem. Int. Ed. 59, 9788-9789 (2020).

13. Viglianti, L. et al. Aggregation-induced emission: mechanistic study of the clusteroluminescence of tetrathienylethene. Chem. Sci. 8, 2629-2639 (2017).

14. $\mathrm{Li}, \mathrm{H}$. et al. Reverse thinking of aggregation-induced emission principle: amplifying molecular motions to boost photothermal efficiency of nanofibers. Angew. Chem. Int. Ed. 59, 20371-20375 (2020).

15. Li, J. et al. Supramolecular materials based on AIE luminogens (AIEgens): construction and applications. Chem. Soc. Rev. 49, 1144-1172 (2020).

16. Jayabharathi, J., Anudeebhana, J., Thanikachalam, V. \& Sivaraj, S. Efficient fluorescent OLEDS based on assistant acceptor modulated HLCT emissive state for enhancing singlet exciton utilization. RSC Adv. 10, 8866-8879 (2020).

17. Yoon, S.-J. et al. Multistimuli two-color luminescence switching via different slip-stacking of highly fluorescent molecular sheets. J. Am. Chem. Soc. 132, 13675-13683 (2010).

18. Yang, J., Fang, M. \& Li, Z. Organic luminescent materials: The concentration on aggregates from aggregation-induced emission. Aggregate 1, 6-18 (2020).

19. Yang, J., Fang, M. \& Li, Z. Stimulus-responsive room temperature phosphorescence in purely organic luminogens. InfoMat 2, 791-806 (2020). 
20. Xie, Y. \& Li, Z. The development of mechanoluminescence from organic compounds: breakthrough and deep insight. Mater. Chem. Front. 4, 317-331 (2020).

21. Huang, J. et al. Similar or totally different: the control of conjugation degree through minor structural modifications, and deep-blue aggregation-induced emission luminogens for non-doped OLEDs. Adv. Funct. Mater. 23, 2329-2337 (2013).

22. Kwok, R. T. K., Leung, C. W. T., Lam, J. W. Y. \& Tang, B. Z. Biosensing by luminogens with aggregation-induced emission characteristics. Chem. Soc. Rev. 44, 4228-4238 (2015).

23. Ravindran, E. \& Somanthan, N. Efficient and thermally stable non-doped red OLEDs based on a "bird-like" donor-acceptor fluorophore with aggregation induced emission enhancement and intramolecular charge transfer. J. Mater. Chem. C. 5, 7436-7440 (2017).

24. Liang, J., Tang, B. Z. \& Liu, B. Specific light-up bioprobes based on AIEgen conjugates. Chem. Soc. Rev. 44, 2798-2811 (2015).

25. La, D. D., Bhosale, S. V., Jones, L. A. \& Bhosale, S. V. Tetraphenylethylenebased AIE-active probes for sensing applications. ACS Appl. Mater. Interfaces 10, 12189-12216 (2018).

26. Wang, D. \& Tang, B. Z. Aggregation-induced emission luminogens for activity-based sensing. Acc. Chem. Res. 52, 2559-2570 (2019).

27. Yuan, Y., Xu, S., Cheng, X., Cai, X. \& Liu, B. Bioorthogonal turn-on probe based on aggregation-induced emission characteristics for cancer cell imaging and ablation. Angew. Chem. Int. Ed. 55, 6457-6461 (2016).

28. Li, J. et al. Exosome-mimetic supramolecular vesicles with reversible and controllable fusion and fission. Angew. Chem. Int. Ed. 59, 21510-21514 (2020).

29. Huang, J. et al. Aggregation-induced emission luminogens married to 2D black phosphorus nanosheets for highly efficient multimodal theranostics. Adv. Mater. 32, 2003382 (2020).

30. $\mathrm{Xu}, \mathrm{W}$. et al. Three-pronged attack by homologous far-red/NIR AIEgens to achieve $1+1+1>3$ synergistic enhanced photodynamic therapy. Angew. Chem. Int. Ed. 59, 9610-9616 (2020).

31. Kang, M. et al. Evaluation of structure-function relationships of aggregationinduced emission luminogens for simultaneous dual applications of specific discrimination and efficient photodynamic killing of Gram-positive bacteria. J. Am. Chem. Soc. 141, 16781-16789 (2019).

32. Liu, L. \& Zhang, J. Gold-catalyzed transformations of a-diazocarbonyl compounds: selectivity and diversity. Chem. Soc. Rev. 45, 506-516 (2016)

33. Davies, H. M. L. \& Hedley, S. J. Intermolecular reactions of electron-rich heterocycles with copper and rhodium carbenoids. Chem. Soc. Rev. 36, 1109-1119 (2007).

34. Ford, A. et al. Modern organic synthesis with a-diazocarbonyl compounds. Chem. Rev. 115, 9981-10080 (2015).

35. Davie, H. M. L. \& Manning, J. R. Catalytic C-H functionalization by metal carbenoid and nitrenoid insertion. Nature 451, 417-424 (2008).

36. Doyle, M. P., Duffy, R., Ratnikov, M. \& Zhou, L. Catalytic carbene insertion into C-H bonds. Chem. Rev. 110, 704-724 (2010).

37. Ma, B., Liu, L. \& Zhang, J. Gold-catalyzed site-selective C-H bond functionalization with diazo compounds. Asian. J. Org. Chem. 7, 2015-2025 (2018).

38. Dong, K., Liu, X.-S., Wei, X., Zhao, Y. \& Liu, L. Borane-catalysed S-H insertion reaction of thiophenols and thiols with $\alpha$-aryl- $\alpha$-diazoesters. Green Synth. Catal. 2, 385-388 (2021).

39. Jana, S., Guo, Y. \& Koenigs, R. M. Recent perspectives on rearrangement reactions of ylides via carbene transfer reactions. Chem. Eur. J. 27, 1270-1281 (2021).

40. Chan, K.-H., Guan, X., Lo, V. K.-Y. \& Che, C.-M. Elevated catalytic activity of ruthenium(II)-porphyrin-catalyzed carbene/nitrene transfer and insertion reactions with N-heterocyclic carbene ligands. Angew. Chem. Int. Ed. 53, 2982-2987 (2014).

41. Chen, K., Zhang, S.-Q., Brandenberg, O. F., Hong, X. \& Arnold, F. H. Alternate heme ligation steers activity and selectivity in engineered cytochrome P450-catalyzed carbene-transfer reactions. J. Am. Chem. Soc. 140, 16402-16407 (2018).

42. $\mathrm{Xu}, \mathrm{B}$. et al. Highly enantioselective $\mathrm{S}-\mathrm{H}$ bond insertion cooperatively catalyzed by dirhodium complexes and chiral spiro phosphoric acids. Chem. Sci. 5, 1442-1448 (2014).

43. Qu, J.-P. et al. Ligand-accelerated asymmetric [1,2]-Stevens rearrangment of sulfur ylides via decomposition of diazomalonates catalyzed by chiral bisoxazoline/copper complex. Adv. Synth. Catal. 351, 308-312 (2009).

44. Thomson, T. \& Stevens, T. S. Degradation of quaternary ammonium salts. Part V. Molecular rearrangement in related sulphur compounds. J. Chem. Soc. 69-73, https://doi.org/10.1039/JR9320000069 (1932).

45. Xu, B. \& Tambar, U. K. Ligand-controlled regiodivergence in the coppercatalyzed [2,3]- and [1,2]-rearrangements of iodonium ylides. J. Am. Chem. Soc. 138, 12073-12076 (2016).
46. Ellis-Holder, K. K., Peppers, B. P., Kovalevsky, A. Y. \& Diver, S. T. Macrocycle ring expansion by double Stevens rearrangement. Org. Lett. 8, 2511-2514 (2006).

47. Zhang, $X$. et al. Catalytic asymmetric [2,3]-sigmatropic rearrangement of sulfur ylides generated from copper(I) carbenoids and allyl sulfides. J. Org. Chem. 67, 5621-5625 (2002).

48. Doyle, M. P., Griffin, J. H., Chinn, M. S. \& Lrusen, D. Rearrangements of ylides generated from reactions of diazo compounds with allyl acetals and thioketals by catalytic methods. Heteroatom acceleration of the [2,3]sigmatropic rearrangement. J. Org. Chem. 49, 1917-1925 (1984).

49. Zhang, Z. et al. Catalytic asymmetric trifluoromethylthiolation via enantioselective [2,3]-sigmatropic rearrangement of sulfonium ylides. Nat. Chem. 9, 970-976 (2017).

50. Hommelsheim, R., Guo, Y., Yang, Z., Empel, C. \& Koenigs, R. M. Blue-lightinduced carbene-transfer reactions of diazoalkanes. Angew. Chem., Int. Ed. 58, 1203-1207 (2019)

51. Ma, M., Peng, L., Li, C., Zhang, X. \& Wang, J. Highly stereoselective [2,3]sigmatropic rearrangement of sulfur ylide generated through $\mathrm{Cu}(\mathrm{I})$ carbene and sulfides. J. Am. Chem. Soc. 127, 15016-15017 (2005).

52. Lin, X. et al. Chiral nickel(II) complex catalyzed enantioselective doyle-kirmse reaction of $\alpha$-diazo pyrazoleamides. J. Am. Chem. Soc. 140, 3299-3305 (2018)

53. Li, Y. et al. Catalytic thia-sommelet-hauser rearrangement: application to the synthesis of oxindoles. Org. Lett. 13, 1210-1213 (2011).

54. Jana, S. \& Koenigs, R. M. Rhodium-catalyzed carbene transfer reactions for sigmatropic rearrangement reactions of selenium ylides. Org. Lett. 21, 3653-3657 (2019).

55. Yang, Z., Guo, Y. \& Koenigs, R. M. Solvent-dependent, rhodium catalysed rearrangement reactions of sulfur ylides. Chem. Commun. 55, 8410-8413 (2019).

56. Wang et al. reported a [1,4]-acyl tranfer form $\mathrm{S}$ to $\mathrm{N}$ via the reaction of 3diazoindol-2-imines with thioesters, dilivering indolyl aryl sufides: Ma, F., Qian, J., Lu, P. \& Wang, Y. Convenient synthesis of 2-amino-3-(arylthio) indoles via the Rh-catalyzed coupling reaction of 3-diazoindol-2-imines with thioesters. Org. Biomol. Chem. 16, 439-443 (2018).

57. $\mathrm{Yu}, \mathrm{Z}$. et al. Highly site-selective direct $\mathrm{C}-\mathrm{H}$ bond functionalization of phenols with $\alpha$-aryl- $\alpha$-diazoacetates and diazooxindoles via gold catalysis. J. Am. Chem. Soc. 136, 6904-6907 (2014).

58. Yu, Z. et al. $\left(\mathrm{C}_{6} \mathrm{~F}_{5}\right)_{3} \mathrm{~B}$ catalyzed chemoselective and ortho-selective substitution of phenols with $\alpha$-aryl $\alpha$-diazoesters. Angew. Chem. Int. Ed. 55, 14807-14811 (2016).

59. Ma, B. et al. Highly para-selective $\mathrm{C}-\mathrm{H}$ alkylation of benzene derivatives with 2,2,2-trifluoroethyl a-aryl-a-diazoesters. Angew. Chem. Int. Ed. 56, 2749-2753 (2017).

60. Becke, A. D. Density-functional thermochemistry. III. The role of exact exchange. J. Chem. Phys. 98, 5648-5652 (1993).

61. Stephens, P. J., Devlin, F. J., Chabalowski, C. F. \& Frisch, M. J. Ab initio calculation of vibrational absorption and circular dichroism spectra using density functional force fields. J. Phys. Chem. 98, 11623-11627 (1994).

62. Lee, C., Yang, W. \& Parr, R. G. Development of the Colle-Salvetti correlationenergy formula into a functional of the electron density. Phys. Rev. B: Condens. Matter Mater. Phys. 37, 785-789 (1988).

63. Frisch, M. J. et al. Gaussian 09, revision D.01 (Gaussian, Inc., 2009).

64. $\mathrm{Xu}, \mathrm{G}$. et al. Access to $\mathrm{N}$-substituted 2-pyridones by catalytic intermolecular dearomatization and 1,4-acyl transfer. Angew. Chem. Int. Ed. 58, 1980-1984 (2019).

\section{Acknowledgements}

We are grateful to the National Natural Science Foundation of China (Nos. 21971066 21772042) and the Science and Technology Commission of Shanghai Municipality (18JC1412300) for financial support. We greatly appreciate Dr. Qiuhua Zhao at East China normal university for her kind help with NMR test, Prof. Xiaoli Zhao at East China normal university for her kind help with X-ray single-crystal structural analyses.

\section{Author contributions}

L.L. conceived the idea; X.-S.L. performed the most experiments; Z.T. assisted in some experiments; Z.T. and M.L. helped in synthesis of substrates 1 and 2. X.-S.L. collected and analyzed the data; Z.L. carried out DFT calculations; L.X. guided the test of photophysical properties; L.L. guided this project and wrote the manuscript.

\section{Competing interests}

The authors declare no competing interests. 


\section{Additional information}

Supplementary information The online version contains supplementary material available at https://doi.org/10.1038/s41467-021-27167-x.

Correspondence and requests for materials should be addressed to Zhiming $\mathrm{Li}$ or Lu Liu.

Peer review information Nature Communications thanks Thomas J. J. Müller, Michael Doyle, Prithvi Vangal and the anonymous reviewer(s) for their contribution to the peer review of this work. Peer reviewer reports are available.

Reprints and permission information is available at http://www.nature.com/reprints

Publisher's note Springer Nature remains neutral with regard to jurisdictional claims in published maps and institutional affiliations. (c) (1) Open Access This article is licensed under a Creative Commons Attribution 4.0 International License, which permits use, sharing, adaptation, distribution and reproduction in any medium or format, as long as you give appropriate credit to the original author(s) and the source, provide a link to the Creative Commons license, and indicate if changes were made. The images or other third party material in this article are included in the article's Creative Commons license, unless indicated otherwise in a credit line to the material. If material is not included in the article's Creative Commons license and your intended use is not permitted by statutory regulation or exceeds the permitted use, you will need to obtain permission directly from the copyright holder. To view a copy of this license, visit http://creativecommons.org/ licenses/by/4.0/.

(C) The Author(s) 2021 